\title{
Estimation of Land Surface Temperature from MODIS Data for the Atmosphere with Air Temperature Inversion Profile
}

\author{
Bo-Hui Tang, Member, IEEE, Chuan zhan, Zhao-Liang Li, Senior, IEEE, Hua Wu and Ronglin Tang
}

\begin{abstract}
Air temperature inversion (ATI) which usually occurs at the near surface boundary layer in the atmosphere influences the thermal path atmospheric upwelling and downwelling radiances. Because it is difficult to determine the occurrence of temperature inversion from satellite data, the influence of ATI on the retrieval of land surface temperature (LST) was not considered in development of LST retrieval algorithm. This paper aims to analyze and reduce the influence of ATI on LST retrieval in the generalized split-window (GSW) algorithm. The GSW coefficients are reparameterized by using the ATI profiles from the Thermodynamic Initial Guess Retrieval (TIGR) cloud-free database. Comparison of the root mean square errors (RMSEs) calculated before and after using the reparameterized coefficients in the GSW algorithm from the numerical simulations showed that the LST retrieval accuracy could be improved by $0.71 \mathrm{~K}$ for viewing zenith angle (VZA) equivalent to $60^{\circ}$. Inter-comparisons using the moderate resolution imaging spectroradiometer (MODIS) products MOD11_L2/MYD11_L2 and in situ LSTs measured at the Hailar field site in northeastern Inner Mongolia, China, showed that the LST retrieval accuracy could be improved by $0.4 \mathrm{~K}$ using the reparamerization coefficients in the GSW algorithm when the atmosphere is occurred by air temperature inversion.
\end{abstract}

Index Terms - Land surface temperature, generalized split-window algorithm (GSW), air temperature inversion (ATI), MODIS.

Manuscript received September 15, 2016; revised October 23, 2016; accepted November 29, 2016; Date of publication $* * * *$; date of current version ****. This work was supported in part by the National Key Research and Development Program of China (NO.2016YFA0600103), in part by the National Natural Science Foundation of China under Grant 41571353 and Grant 41231170, and in part by the Innovation Project of LREIS (O88RA801YA). (Corresponding author: Bo-Hui Tang)

B.-H. Tang is with the State Key Laboratory of Resources and Environment Information System (LREIS), Institute of Geographic Science and Nature Resources Research (IGSNRR), Chinese Academy of Sciences (CAS), Beijing 100101, China, with the University of Chinese Academy of Sciences (UCAS), and also with the Jiangsu Center for Collaborative Innovation in Geographical Information Resource Development and Application, Nanjing 210023, China (e-mail: tangbh@igsnrr.ac.cn).

C. Zhan, H. Wu, and R. Tang are with the LREIS, IGSNRR, CAS, and also with the UCAS (e-mail: zhanc.14s@igsnrr.ac.cn, wuhua@igsnrr.ac.cn, trl_wd@163.com).

Z.-L. Li is with the LREIS, IGSNRR, CAS, with the Key Laboratory of Agri-informatics, Ministry of Agriculture/Institute of Agricultural Resources and Regional Planning, Chinese Academy of Agricultural Sciences, Beijing 100081, China, and also with the ICube, UdS, CNRS, 67412 Illkirch, France (e-mail: lizhaoliang@caas.cn).

\section{INTRODUCTION}

T AND surface temperature (LST) is a key parameter which controls the fundamental biospheric and geospheric interactions between Earth's surface and its atmosphere [1]. Knowledge of reliable estimates of LST is crucial because many applications in climatological, hydrological, ecological, and biogeochemical studies are relied on it [2-4].

Up to now, many algorithms have been developed for retrieving LST from polar-orbit satellite thermal infrared (TIR) data [5-12] and geostationary satellite TIR data [13-16]. Li et al. [17] pointed out that accurate retrieval of LST from satellite data requires both atmospheric and emissivity corrections. Many efforts have been carried out to deal with atmospheric and emissivity effects [18-22]. Fan et al. [23] recently analyzed the influence of dust aerosol on the LST retrieval error of the generalized split-window (GSW) algorithm [14] and proposed a linear function associated with the aerosol optical depth to reduce the LST retrieval error under dust aerosol conditions. However, the influence of the anomalous air temperature profile in the atmosphere on retrieving LST from satellite data has not been considered in the development of LST retrieval algorithm.

Air temperature inversion (ATI) profile refers to the atmosphere containing temperature anomalies in the lower troposphere. It is well known that the anomalies usually occur in remote mountainous regions since the cold air tends to stay in the valley during the night. Mutiibwa et al. [24] analyzed the relationship between satellite-derived LST and surface air temperature in complex mountainous topography and found that the relation was strongest during late summer and fall, and weakest during winter and early spring. Because it is difficult to determine the anomalies from remotely sensed data, few studies have considered reducing the influences of ATI atmosphere on the retrieval of surface temperature. Minnett first noted this influence on the retrieval of sea surface temperature (SST). He pointed out that this influence could cause a few tenths of a kelvin on the SST retrieval [25]. Platt et al. [26] found that atmospheric temperature anomalies often occurred during clear nights and that the influence of the anomalies on LST retrieval was related to the water vapor and the land surface emissivity (LSE). Lagouarde et al. [27] also illustrated that the turbulence of the atmosphere could induce extra LST retrieval error. Therefore, it is critical to analyze the influence of ATI atmosphere on the LST retrieval. 
The objective of this study focuses on two aspects: 1) analyze the influence of ATI atmosphere on LST retrieval in the GSW algorithm and 2) reparameterize the GSW coefficients and reduce the LST retrieval errors caused by ATI atmosphere. Section II introduces the data and test site. Section III analyzes the influence of ATI atmosphere on the LST retrieval accuracy. The LST retrieved with GSW algorithm under ATI atmosphere is also described in this Section. Section IV shows the results of retrieval LST for ATI atmospheres. Some preliminary validations with the moderate resolution imaging spectroradiometer (MODIS) LST products and in situ measurements are also shown in this Section. Finally, the conclusions are given in Section V.

\section{DAta And Test Site}

\section{A. Air Temperature Inversion Profile Datasets}

The Thermodynamic Initial Guess Retrieval (TIGR) database [28] constructed by the Laboratoire de Meteorologie Dynamique (LMD) is used. The database contains 2311 atmospheric temperature, humidity, and ozone mixing ratio profiles selected from collections of more than 150000 radiosonde measurements around the world. The profiles represent a worldwide set of atmospheric situations from polar to tropical atmospheres with water vapor content (WVC) varied from 0.1 to $8.0 \mathrm{~g} / \mathrm{cm}^{2}$ and atmospheric temperature ranging from $231 \quad \mathrm{~K} \quad$ to $\quad 315 \quad \mathrm{~K}$ (http://ara.lmd.polytechnique.fr/htdocs-public/products/TIGR/ TIGR.html).

To get ATI atmospheric profiles for clear skies, the atmospheric profiles with relative humidity (RH) not greater than $90 \%$ and air temperature at one higher altitude larger than that at lower altitude near land surface boundary are selected. In total, 267 ATI atmospheric profiles for cloud-free conditions are extracted for the analysis.

\section{B. MODIS Satellite Data}

MODIS, a sensor on NASA's Earth Observing System Terra platform launched in 1999 and Aqua platform launched in 2002, is a passive imaging sensor including 36 channels with spectra changing from 0.4 to $14.0 \mu \mathrm{m}$ [29]. It provides comprehensive and frequent global earth imaging at variable spatial resolution with nadir footprints no more than $1 \mathrm{~km}$. Furthermore, MODIS provides various products for many land/ocean applications. In this study, four types of MODIS products provided by the NASA Goddard Space Flight Center (GSFC) Level 1 and Atmosphere Archive and Distribution System (LAADS) (http://ladsweb.nascom.nasa.gov/data/search.html) are used. The data are MOD021KM/MYD021KM, MOD03/MYD03, MOD11_L2/MYD11_L2, MOD35_L2/ MYD35_L2.

The MOD021KM/MYD021KM products are earth view level_1B data with $1-\mathrm{km}$ resolution at nadir, which contain radiances and reflectances measured at the top of atmosphere (TOA). The MOD03/MYD03 products are the geolocation field's data consisting of geodetic latitude, longitude, solar zenith and azimuth angles, and satellite zenith and azimuth angles for each 1-km sample. The MOD11_L2/MYD11_L2 products provide LST and emissivity values at $1-\mathrm{km}$ resolution. The MOD35_L2/MYD35_L2 products are cloud mask data assigning a clear sky confidence level (i.e., clear, probably clear, uncertain, and cloudy) to each instantaneous field of view (IFOV).

\section{In Situ Measurements}

The Hailar site $\left(49^{\circ} 21^{\prime} \mathrm{N}, 120^{\circ} 07^{\prime} \mathrm{E}\right)$, located in Northeastern Inner Mongolia, China is selected as the study site. The field site is covered by a homogeneous grass and has a semi-humid and semi-arid continental monsoon climate, with a mean annual temperature of $-2^{\circ} \mathrm{C}$ and a mean annual rainfall of about $350 \mathrm{~mm}$.

Four infrared radiometers SI-111, manufactured by the Apogee Instruments, Inc., USA, were linearly installed at an interval of $120 \mathrm{~m}$ at the study site. Because the land cover of the site is homogeneous grass, the mean of four radiometers measurements are used to represent the pixel size of $1 \mathrm{~km}$. Each radiometer was mounted at a height of $2.0 \mathrm{~m}$ to observe an area of about $2.0 \mathrm{~m}^{2}$. The radiometer measured the TIR radiance in the spectral domain of 8.0-14.0 $\mu \mathrm{m}$ and obtained brightness temperatures with an absolute accuracy of $\pm 0.2 \mathrm{~K}$. An additional radiometer was directed toward the sky at $53^{\circ}$ in terms of the zenith and measured the downwelling atmospheric radiance [30].

To determine whether anomalous temperature atmosphere occurs or not, the radiosonde data from College of Engineering, University of Wyoming are used. (http://weather.uwyo.edu/upperair/sounding.html). The radiosonde data were picked up twice a day $(0 \mathrm{a} . \mathrm{m}$. and 12 a.m. at local time) from Hailar station $\left(49.21^{\circ} \mathrm{N}, 119.75^{\circ} \mathrm{E}\right)$, which is about $30 \mathrm{~km}$ distance from the study site. The overpass times of Terra and Aqua satellites are about 11 a.m. and 13 p.m. at local time, respectively. Although there is spatial-temporal mismatch between the radiosonde data and satellite data, the radiosonde data can still be used to depict the atmospheric condition of the study site. This is because the Hailar region is flatland and the field campaigns were conducted in late autumn and winter when the weather usually changed not significantly within a short time.

\section{LST RETRIEVAL FOR AIR TEMPERATURE INVERSION ATMOSPHERE}

\section{A. Generalized split-window algorithm}

Wan and Dozier [8] proposed a generalized split-window (GSW) algorithm to retrieve LST from MODIS satellite data for clear skies. According to GSW algorithm, the LST can be retrieved by

$$
T_{s}=a_{0}+\left(a_{1}+a_{2} \frac{1-\varepsilon}{\varepsilon}+a_{3} \frac{\Delta \varepsilon}{\varepsilon^{2}}\right) \frac{\left(T_{i}+T_{j}\right)}{2}+\left(a_{4}+a_{5} \frac{1-\varepsilon}{\varepsilon}+a_{6} \frac{\Delta \varepsilon}{\varepsilon^{2}}\right) \frac{\left(T_{i}-T_{j}\right)}{2},
$$

where $T_{s}$ represents the LST (hereafter, LST is used interchangeably with $\left.T_{s}\right), \varepsilon=\left(\varepsilon_{\mathrm{i}}+\varepsilon_{j}\right) / 2, \Delta \varepsilon=\varepsilon_{i}-\varepsilon_{j}$ and $\varepsilon_{i}$ and $\varepsilon_{j}$ are the land surface emissivities (LSE, hereafter, LSE is used interchangeably with $\varepsilon_{i}$ ) in channels $i$ and $j$, respectively. $T_{i}$ and $T_{j}$ are respectively the TOA brightness temperatures measured in channels $i$ and $j$ (for MODIS data, $i=31$ and $j=32$ ). $a_{0}-a_{6}$ are coefficients derived from simulated data. 
To determine the coefficients $a_{0}-a_{6}$, Wan and Dozier divided the simulated brightness temperatures at the top of atmosphere (TOA) into several sub-ranges by averaged emissivity, atmospheric water vapor content (WVC) and atmospheric air temperature near the surface. Considering that it is difficult to obtain the atmospheric air temperature simultaneously at the satellite overpasses, Tang et al. [14] proposed using an approximate LST to substitute the air temperature, and made the GSW algorithm more practical. Tang et al.'s method is adopted in this work to retrieve LST.

B. Influence of Air Temperature Inversion Atmosphere on LST Retrieval

Fig.1 (a) shows, for instance, a normal atmospheric profile from TIGR database while Fig.1 (b) illustrates one anomalous atmospheric profile. As shown the red rectangle in Fig.1 (b), the air temperature is increased with the altitude near the surface boundary.

To better analyze how significant the effect of anomalous temperature atmosphere on the accuracy of LST retrieval, the normal atmospheric temperature profile was changed manually to an anomalous one. First we find out the value of the atmospheric temperature of a normal profile at the altitude of 3 $\mathrm{km}(3 \mathrm{~km}$ is chosen because no ATI is found above $3 \mathrm{~km}$ among all the ATI profiles in TIGR database). Then we calculate the rest of the values below $3 \mathrm{~km}$ based on the ATI intensity and replace the normal original atmospheric temperatures with the calculated ones. Subsequently, we retrieve the LST from the TOA brightness temperatures simulated with the normal atmosphere using the coefficients of GSW algorithm. Then, we retrieve the LST from the TOA brightness temperature simulated using the changed atmospheric temperature profile with the same GSW coefficients.

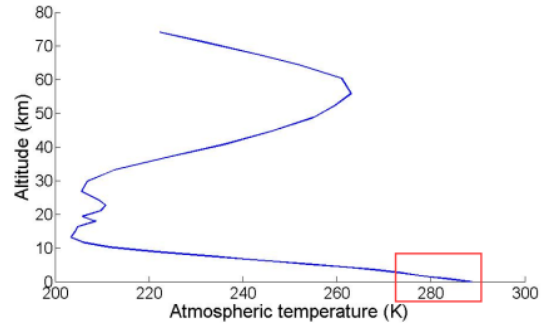

(a)

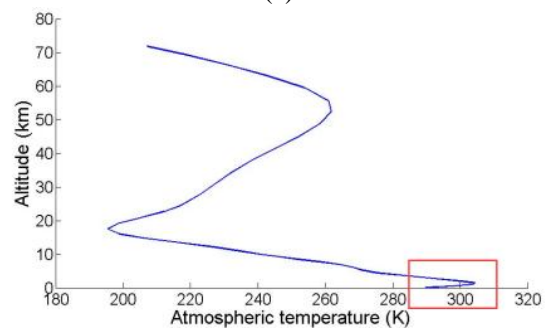

(b)

Fig.1 Atmospheric temperature profiles: (a) normal profile, and (b) air temperature inversion profile.

Fig. 2 shows the root mean square errors (RMSE) between the retrieval and actual LST for different anomalous temperature atmospheres for different viewing zenith angles (VZAs).

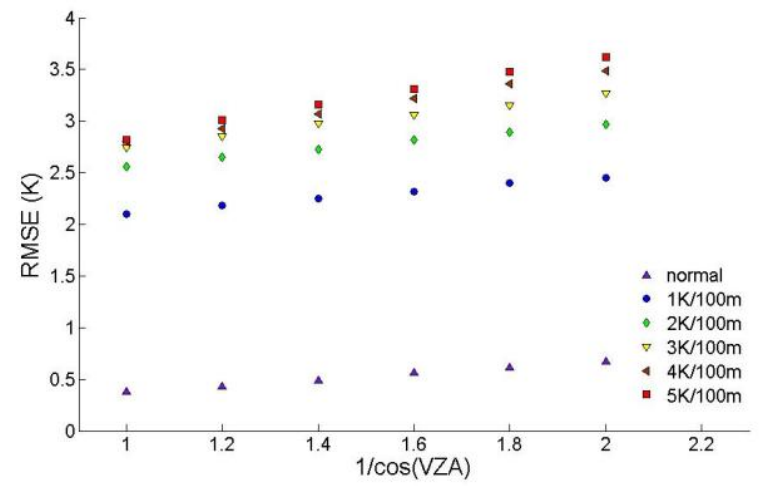

Fig.2 RMSEs between the retrieved and actual LSTs as functions of the secant VZA for different intensities of temperature inversion.

Here, an intensity of temperature inversion is used, which is defined as

$$
\mathrm{I}=\frac{\Delta T}{\Delta H} \times 100=\frac{T_{2}-T_{1}}{H_{2}-H_{1}} \times 100,
$$

in which $\mathrm{I}$ is the intensity, $\mathrm{T}_{1}$ is the air temperature at the low inversion layer, $\mathrm{T}_{2}$ is the air temperature at the top inversion layer. $\mathrm{H}_{1}$ is the altitude corresponding to $\mathrm{T}_{1}$ and $\mathrm{H}_{2}$ is the altitude corresponding to $\mathrm{T}_{2}$.

Table I gives the resultant RMSEs of retrieval LSTs for different VZAs and different intensities. From Fig.2 and Table I, we can see that the influence of ATI on the accuracy of retrieval LST is increased with the increase of the VZA and intensity, respectively. The intensity of temperature inversion has significant influence on the LST retrieval accuracy. All values of RMSE are above $2.0 \mathrm{~K}$ when the intensity is above 1 $\mathrm{K} / 100 \mathrm{~m}$, and the maximum RMSE could reach $3.62 \mathrm{~K}$ for intensity $=5$ and $\mathrm{VZA}=60^{\circ}$, which implies that it is essential to take into account the influence of the ATI atmosphere on the LST retrieval.

TABLE I. RMSES OF RETRIEVAL LST FOR DIFFERENT VZAS AND DIFFERENT INTENSITIES OF TMPERATURE INVERSION

\begin{tabular}{ccccccc}
\hline $\begin{array}{c}\text { Intensity } \\
(\mathrm{K} / 100 \mathrm{~m})\end{array}$ & $0^{\circ}$ & $33.56^{\circ}$ & $44.42^{\circ}$ & $51.32^{\circ}$ & $56.25^{\circ}$ & $60^{\circ}$ \\
\hline$/$ & 0.38 & 0.43 & 0.49 & 0.56 & 0.61 & 0.67 \\
1 & 2.10 & 2.18 & 2.25 & 2.32 & 2.40 & 2.45 \\
2 & 2.56 & 2.65 & 2.73 & 2.82 & 2.89 & 2.97 \\
3 & 2.74 & 2.85 & 2.98 & 3.06 & 3.15 & 3.27 \\
4 & 2.80 & 2.93 & 3.07 & 3.22 & 3.36 & 3.49 \\
5 & 2.82 & 3.01 & 3.16 & 3.31 & 3.48 & 3.62 \\
\hline
\end{tabular}

Note that Tang et al.'s scheme [14] did not distinguish the anomalous temperature profiles from the TIGR database in determining the coefficients of the GSW algorithm. We analyze first the influence of the ATI atmospheres on the accuracy of LST retrieval. Fig.3(a) shows the histograms of the difference between the actual LSTs and the ones estimated for the entire involved atmospheric profiles with LST varying from $275 \mathrm{~K}$ to $295 \mathrm{~K}$, LSE ranging from 0.90 to 0.96 , and $\mathrm{WVC}$ changing from $1.0 \mathrm{~g} / \mathrm{cm}^{2}$ to $2.5 \mathrm{~g} / \mathrm{cm}^{2}$ for VZA $=0^{\circ}$. The bias and RMSE are 0 and $0.41 \mathrm{~K}$, respectively. Meanwhile, The differences of the LST retrieval error calculated for the ATI profiles at the same sub-range are shown in Fig.3(b). The bias and RMSE in this case are $0.36 \mathrm{~K}$ and $0.59 \mathrm{~K}$, respectively. It is obvious that 
LST retrieval accuracy is decreased by the occurrence of ATI profiles.

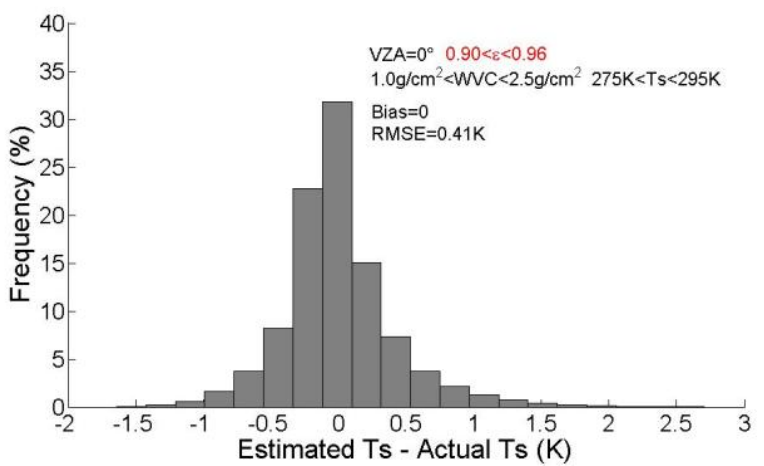

(a)

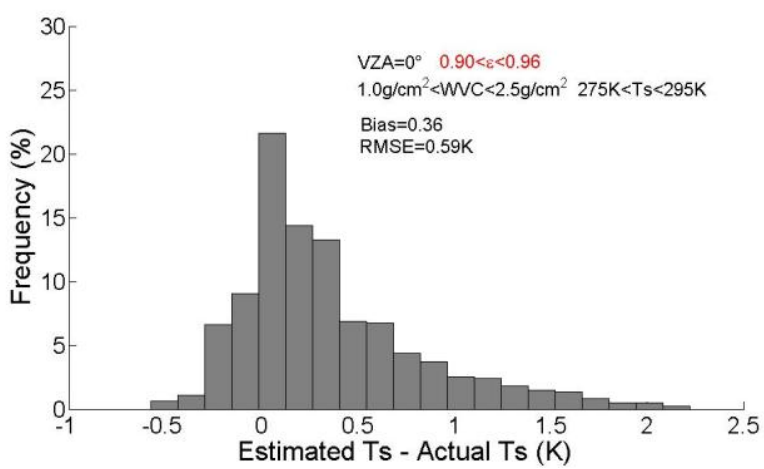

(b)

Fig.3. Histogram of the difference between the estimated and actual Ts for the sub-range with LST varying from $275 \mathrm{~K}$ to $295 \mathrm{~K}$, LSE from 0.90 to 0.96 , and WVC from $1.0 \mathrm{~g} / \mathrm{cm}^{2}$ to $2.5 \mathrm{~g} / \mathrm{cm}^{2}$ : (a) for the entire profiles, and (b) for the anomalous temperature profiles.

In addition, Fig. 4 gives the RMSEs between the actual and estimated LST as functions of the secant VZA for the entire profiles and the ATI profiles, respectively. As shown in this figure, the RMSEs increase with the increase of the VZA. It is worth noting that the differences of the RMSEs calculated for the entire profiles and the corresponding ATI profiles are also increased with the increase of VZA. The RMSE differences increase from $0.18 \mathrm{~K}$ to $0.29 \mathrm{~K}$ for the low emissivity group $(0.90 \leq \varepsilon \leq 0.96)$ and from $0.17 \mathrm{~K}$ to $0.25 \mathrm{~K}$ for the high emissivity group $(0.94 \leq \varepsilon \leq 1.0)$ when the VZA changes from $0^{\circ}$ to $60^{\circ}$, indicating that air temperature inversion in the low atmospheric profile has greater influence on the accuracy of LST retrieval when the VZA is larger.

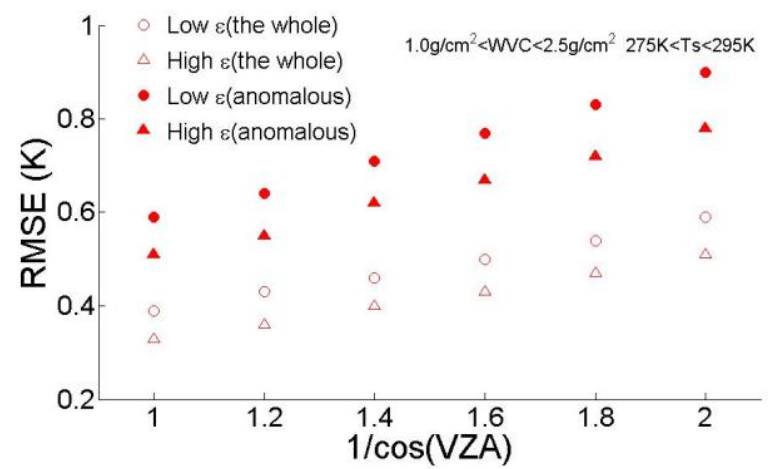

Fig.4. RMSEs between the estimated and actual LST as functions of the secant VZA for the entire profiles and the air temperature inversion profiles in two different emissivity groups. (Low $\varepsilon$ represents the emissivity ranging from 0.90 to 0.96 , and high $\varepsilon$ represents the emissivity varying from 0.94 to 1.0 )

\section{Reparametrization of the GSW Coefficients}

Similar to Tang et al.' scheme [14], a simulation database of the TOA brightness temperatures for the MODIS thermal infrared (TIR) channels 31 and 32 is established with the latest atmospheric radiative transfer model MODTRAN 5 and the TIGR cloud-free ATI atmospheric profiles.

The simulated TOA brightness temperatures are divided into several sub-ranges for each VZA, according to the values of the average emissivity $\varepsilon$, the WVC, and the LST. The $\varepsilon$ is divided into two groups: $0.90 \leq \varepsilon \leq 0.96,0.94 \leq \varepsilon \leq 1.0$. The WVC is divided into six groups: [0, 1.5], [1.0, 2.5], [2.0,3.5], [3.0, 4.5], $[4.0,5.5]$, and $[5.0,6.5] \mathrm{g} / \mathrm{cm}^{2}$. The LST, $T_{s}$, is divided into five sub-ranges: $T_{s} \leq 280 \mathrm{~K}, 275 \leq T_{s} \leq 295 \mathrm{~K}, 290 \leq T_{s} \leq 310 \mathrm{~K}$, $305 \leq T_{s} \leq 325 \mathrm{~K}, T_{s} \geq 320 \mathrm{~K}$.

To reduce the influence of the ATI atmosphere and to improve the accuracy of the LST retrieval under ATI atmospheric condition, the GSW coefficients in equation (1) are fitted alone through statistical regression method for each VZA and each sub-range. Fig.5 displays an example the coefficients for six VZAs $\left(0^{\circ}, 33.56^{\circ}, 44.42^{\circ}, 51.32^{\circ}, 56.25^{\circ}\right.$, $60^{\circ}$ ), for the sub-range with LST varying from $275 \mathrm{~K}$ to $295 \mathrm{~K}$, WVC from 0 to $1.5 \mathrm{~g} / \mathrm{cm}^{2}$, and $\varepsilon$ from 0.94 to 1.0 . The coefficients for other VZAs can be linearly interpolated in function of the secant VZA for this sub-range. Similar results are also obtained for other sub-ranges.

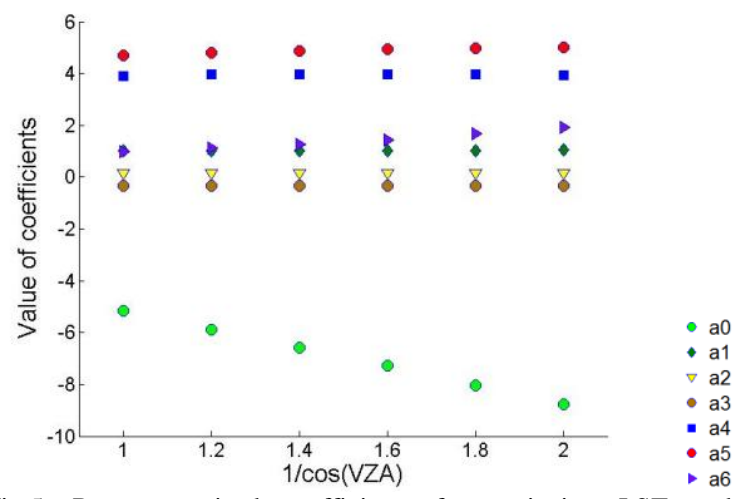

Fig.5. Reparameterized coefficients for retrieving LST under the air temperature inversion atmospheric conditions for the sub-range with LST varying from $275 \mathrm{~K}$ to $295 \mathrm{~K}$, WVC from 0 to $1.5 \mathrm{~g} / \mathrm{cm}^{2}$, and $\varepsilon$ from 0.94 to 1.0 .

\section{RESULTS AND VALIDATIONS}

A. Estimation of LST for Air Temperature Inversion Atmosphere

Fig.6 illustrates the histograms of the differences between the actual LSTs and those estimated with the reparamerization coefficients in the GSW algorithm for the ATI atmospheric profiles. The RMSE is $0.33 \mathrm{~K}$ for the high emissivity group $\varepsilon$ $\in[0.94,1.0]$, and $0.38 \mathrm{~K}$ for the other low emissivity group $\varepsilon$ $\in[0.90,0.96]$, for the sub-range WVC $\in[1.0,2.5], \mathrm{Ts} \in[275 \mathrm{~K}$, $295 \mathrm{~K}]$ and $\mathrm{VZA}=0^{\circ}$. 


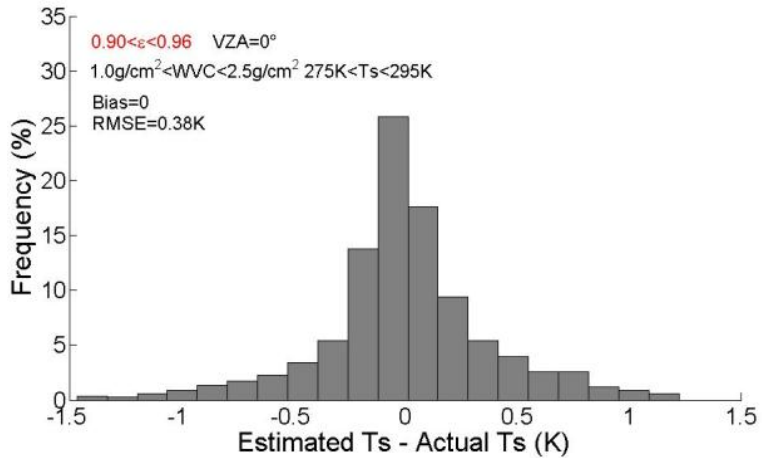

(a)

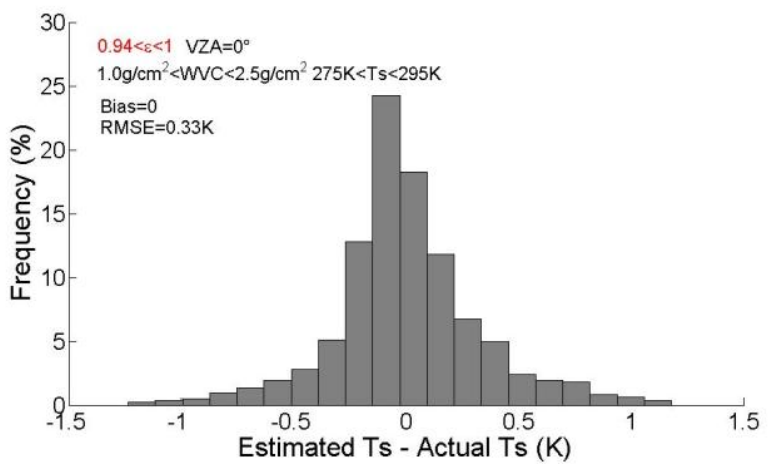

(b)
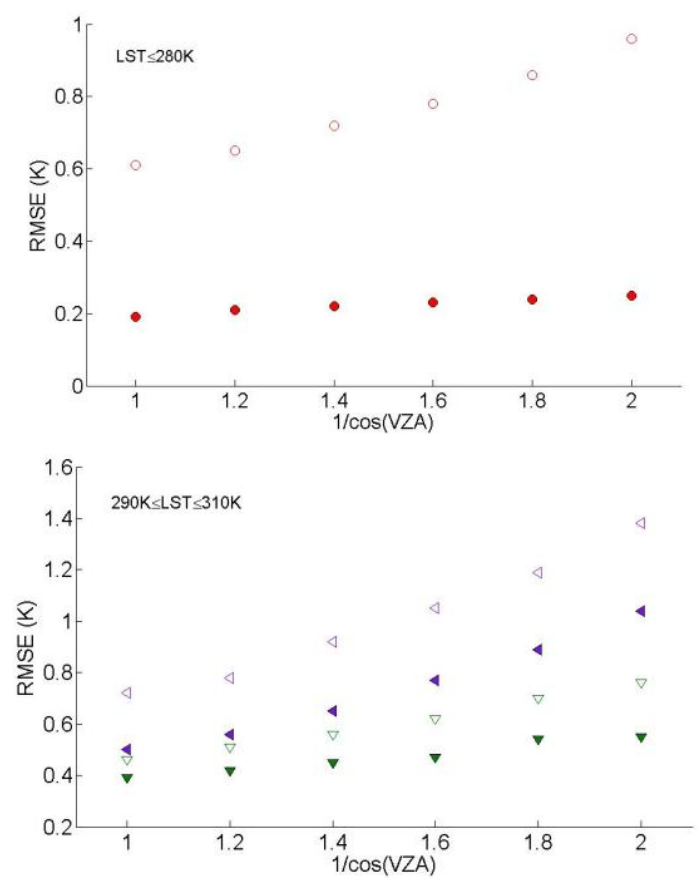

Fig.6. Histogram of the difference between the LSTs estimated with the reparameterized coefficients and the actual ones, for the sub-range with LST varying from $275 \mathrm{~K}$ to $295 \mathrm{~K}$, and WVC from $1.0 \mathrm{~g} / \mathrm{cm}^{2}$ to $2.5 \mathrm{~g} / \mathrm{cm}^{2}$. (a) for $\varepsilon$ $\in[0.90,0.96]$, and (b) for $\varepsilon \in[0.94,1.0]$.

From Fig. 3(b) and Fig. 6(a), one can see that the value of RMSE changes from $0.59 \mathrm{~K}$ to $0.38 \mathrm{~K}$ with a decrease of $0.21 \mathrm{~K}$ for the sub-range WVC $\in[1.0,2.5]$ and $\mathrm{Ts} \in[275 \mathrm{~K}, 295 \mathrm{~K}]$ for the low emissivity group. For the high emissivity group of this sub-range, we get the similar result with RMSE decrease of $0.18 \mathrm{~K}$.

Fig.7 shows comparisons of the RMSEs calculated before (hollow labels) and after (solid labels) using the reparameterized coefficients in the GSW algorithm to retrieve LST for the entire sub-ranges for the low emissivity group. As seen from this figure, the RMSEs of the retrieval LSTs are significantly decreased, especially for the sub-range WVC $\in$ $[1.0,2.5], \mathrm{LST} \leq 280 \mathrm{~K}$ with RMSE decreased by $0.71 \mathrm{~K}$ for $\mathrm{VZA}=60^{\circ}$. This is because the influence of the temperature profile on the LST retrieval in the dry atmosphere is larger than that in the wet atmosphere. It should be pointed out here that there are no ATI profiles with WVC above $5.5 \mathrm{~g} / \mathrm{cm}^{2}$ and LST above $310 \mathrm{~K}$ in the TIGR database, the comparisons of RMSE for those sub-ran ges are not performed in this work.
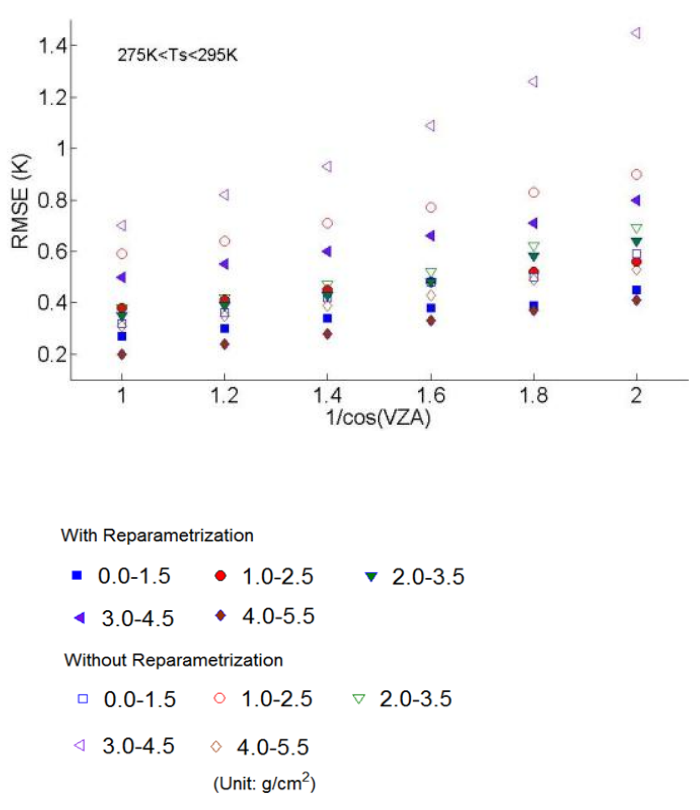

Fig.7. Comparison of RMSE between the estimated and actual LST retrieved with/without using the reparameterized coefficients for the low emissivity group. (Solid labels represent the results obtained with reparameterization coefficients while hollow labels represent the opposite)

\section{B. Validation Using In Situ Measurements}

To validate the performance of the reparameterization of the GSW coefficients for retrieving LST under the atmospheres with air temperature inversion profile, some in situ measurements conducted in the Hailar field site are used. Because the in situ measurement observed by the infrared radiometer is ground-based radiance, which is coupled by LST, LSE and downwelling atmospheric radiance. Ignoring the effect of atmosphere between the ground and radiometer, the LST can be derived by

$$
L S T=B_{\lambda}^{-1}\left[\frac{1}{\varepsilon_{\lambda}}\left(\mathrm{L}_{\text {ground }, \lambda}-\left(1-\varepsilon_{\lambda}\right) R_{\text {atm, } \lambda}^{\downarrow}\right)\right],
$$


in which $B^{-1}$ is the inversion of the Planck function, $L_{\text {ground }, \lambda}$ is the ground-based radiance emitted from the surface, $\varepsilon_{\lambda}$ is the spectral LSE, and $R_{a t m, \lambda}^{\downarrow}$ is the spectral downwelling radiance from the sky, which can be obtained from measurements by an additional SI-111 infrared radiometer directed towards the sky.

Note that the Hailar field site is located in Northeastern Inner Mongolia, China, the air temperature inversion atmosphere usually occurs in late autumn and winter [31]. Consequently, four months, i.e., November and December in 2013, and January and February in 2014, during the field campaigns period are chosen for the validation. In order to guarantee cloud-free condition at the time of satellite overpasses, the MODIS cloud mask products MOD35_L2/MYD35_L2 with clear-sky confidence level are used. The images with clear pixel of the study site are chosen in the first step for pre-processing the MOD021KM/MYD021KM data. In addition, the radiosonde data provided by the College of Engineering, University of Wyoming are used to judge whether ATI atmosphere occurs or not at the satellite overpasses. Finally, in total, 14 scenes of MOD021KM data and 18 scenes of MYD021KM data are meet the requirement of the validation. Fig. 8 presents the number of cloud-free days with anomalous air temperature condition at the time of MODIS overpasses during the experimental period at the field site.

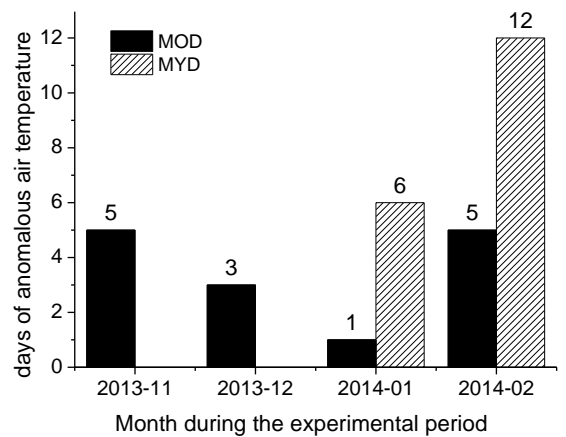

Fig.8. number of cloud-free days with air temperature inversion atmospheres at the time of MODIS overpasses during the experimental period at the field site.

Fig.9 illustrates the used atmospheric temperature profiles. The solid lines representing the atmospheric profiles correspond to the overpass time of MODIS/Terra satellite, and the dashed lines are the profiles associated with the overpasses of MODIS/Aqua satellite. As seen in this figure, the air temperature inversion usually occurs at the surface boundary with altitude below $3.0 \mathrm{~km}$.

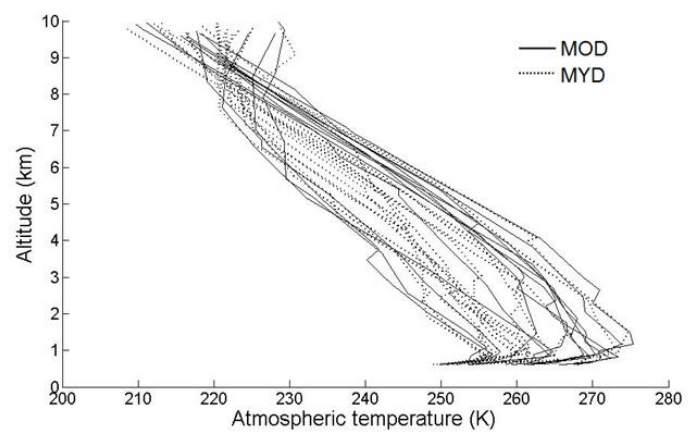

Fig.9. Atmospheric temperature profiles from the radiosonde data provided by the College of Engineering, University of Wyoming.

Note that the land cover of the Hailar field site was covered by snow from November 6, 2013, to Match 25, 2014, the value of $\varepsilon_{i}$ in equation (3) is assigned a constant value of 0.988 , calculated by integrating the spectral response function of the SI-111 radiometer with the snow spectra provided by the MODIS UCSB (University of California, Santa Barbara) emissivity library of the MODIS LST group (http://www.icess.ucsb.edu/modis/EMIS/html/em.html).

Fig.10 shows the comparisons between the LSTs calculated using in situ measurements, estimated from MODIS level_1B data with the proposed method, and those extracted from MODIS LST products MOD11_L2/ MYD11_L2, respectively. The bias and RMSE of LSTs between in situ measurements and the MOD11_L2 product are $-1.05 \mathrm{~K}$ and $1.83 \mathrm{~K}$, while they are $-0.60 \mathrm{~K}$ and $1.47 \mathrm{~K}$ for the comparison between in situ measurements and ones estimated with our proposed method. The bias and RMSE are $-0.70 \mathrm{~K}$ and $1.14 \mathrm{~K}$ for the comparison of in situ measurements and the MYD11_L2 product, and they are $-0.15 \mathrm{~K}$ and $0.72 \mathrm{~K}$ for comparing in situ measurements with the ones estimated using our proposed method. From the comparisons, we can conclude that the accuracy of LST retrieved from MODIS data with GSW algorithm could be improved approximately $0.4 \mathrm{~K}$ by using our reparameterization coefficients when the atmosphere is occurred by air temperature inversion profile.



(a) 


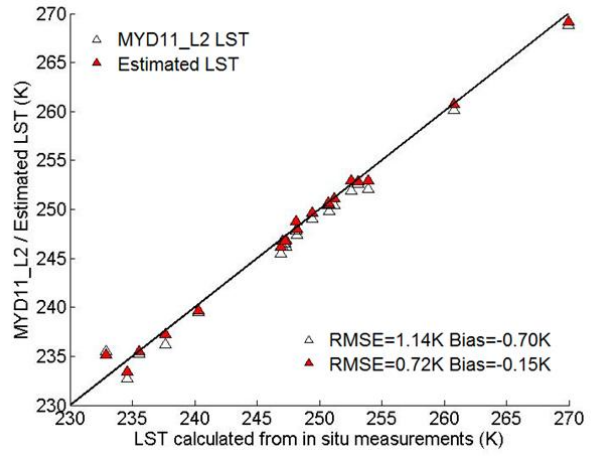

(b)

Fig.10. Comparison between the LSTs calculated using in situ measurements, estimated from MODIS level_1B data with the proposed method, and those extracted from MODIS LST products, respectively. (a) For MOD11_L2 product, and (b) for MYD11_L2 product.

\section{CONCLUSION}

This paper has analyzed the influence of the ATI occurred at the near surface boundary layer of the atmosphere on the LST retrieved from MODIS data with the GSW algorithm. The analysis results showed that the LST retrieval error increased with the increase of the intensity of ATI in the atmosphere and the VZA, respectively. The RMSE could reach $3.62 \mathrm{~K}$ for intensity $=5$ and $\mathrm{VZA}=60^{\circ}$.

To reduce the influence of the ATI atmosphere on the LST retrieval, the temperature inversion profiles from the TIGR database were chosen to simulate the brightness temperatures for MODIS satellite data with the latest atmospheric radiative transfer model MODTRAN 5. The GSW coefficients were reparameterized to retrieve LST for the ATI atmospheres. Comparison of the RMSEs calculated before and after using the reparameterized coefficients in the GSW algorithm from the numerical simulations showed that the LST retrieval accuracy could be improved by $0.71 \mathrm{~K}$ for WVC varying from $1.0 \mathrm{~g} / \mathrm{cm}^{2}$ to $2.5 \mathrm{~g} / \mathrm{cm}^{2}, \mathrm{LST} \leq 280 \mathrm{~K}$, and $\mathrm{VZA}=60^{\circ}$.

To validate the performance of the proposed method, the MODIS LST products MOD11_L2/MYD11_L2 with LST retrieved using the GSW algorithm at 1-km spatial resolution, and some in situ measurements at the Hailar field site in northeastern Inner Mongolia, China, were used. The results showed that the RMSEs between LSTs from MOD11_L2/MYD11_L2 products and the in situ measurements were $1.83 \mathrm{~K}$ and $1.14 \mathrm{~K}$, while they were $1.47 \mathrm{~K}$ and $0.72 \mathrm{~K}$ between those estimated with our proposed method and the in situ measurements associated with Terra and Aqua satellites overpass times, respectively. It is indicated that our proposed method could improve the LST retrieval accuracy by $0.4 \mathrm{~K}$ for the GSW algorithm from MODIS satellite data when the atmosphere is occurred by air temperature inversion.

\section{REFERENCES}

[1] H. Mannstein, Surface Energy Budget, Surface Temperature and Thermal Inertia: Springer Netherlands, 1987.

[2] J. D. Kalma, T. R. Mcvicar, and M. F. Mccabe, "Estimating Land Surface Evaporation: A Review of Methods Using Remotely Sensed Surface Temperature Data," Surveys in Geophysics, vol. 29, pp. 421-469, 2008.

[3] Z.-L. Li, R. Tang, Z. Wan, Y. Bi, C. Zhou, B. Tang, et al., "A review of current methodologies for regional evapotranspiration estimation from remotely sensed data," Sensors, vol. 9, pp. 3801-53, 2009.
[4] B.-H. Tang, and Z.-L. Li, "Estimation of instantaneous net surface longwave radiation from MODIS cloud-free data," Remote Sensing of Environment, vol. 112, pp. 3482-3492, 2008.

[5] F. Becker and Z.-L. Li, "Temperature-independent spectral indices in thermal infrared bands," Remote Sensing of Environment, vol. 32, pp. 17-33, 1990.

[6] Z.-L. Li and F. Becker, "Feasibility of land surface temperature and emissivity determination from AVHRR data," Remote Sensing of Environment, vol. 43, pp. 67-85, 1993.

[7] J. A Sobrino, Z.-L. Li, M.P. Stoll, and F. Becker, "Improvements in the split-window technique for land surface temperature determination," IEEE Transections on Geoscience and Remote Sensing , vol. 32, pp. 243-253, 1994.

[8] Z. Wan and J. Dozier, "A generalized split-window algorithm for retrieving land-surface temperature from space," IEEE Transactions on Geoscience \& Remote Sensing, vol. 34, pp. 892-905, 1996.

[9] Z. Wan and Z.-L. Li, "A physics-based algorithm for retrieving land-surface emissivity and temperature from EOS/MODIS data," IEEE Transactions on Geoscience \& Remote Sensing, vol. 35, pp. 980-996, 1997.

[10] A. Gillespie, S. Rokugawa, T. Matsunaga, and J. S. Cothern, "A temperature and emissivity separation algorithm for Advanced Spaceborne Thermal Emission and Reflection Radiometer (ASTER) images," IEEE Transactions on Geoscience \& Remote Sensing, vol. 36, pp. 1113-1126, 1998.

[11] Z. Wan and Z.-L. Li, "Radiance-based validation of the V5 MODIS landsurface temperature product," International Journal of Remote Sensing, vol. 29, pp. 5373-5395, 2008.

[12] B.-H. Tang, K. Shao, Z.-L. Li, H. Wu, F. Nerry, and G. Zhou, "Estimation and Validation of Land Surface Temperatures from Chinese Second-Generation Polar-Orbit FY-3A VIRR Data," Remote Sensing, vol. 7, pp. 3250-3273, 2015

[13] J. A. Sobrino, and M. Romaguera, "Land surface temperature retrieval from MSG1-SEVIRI data," Remote Sensing of Environment, vol. 92, pp. 247-254, 2004.

[14] B.-H. Tang, Y. Bi, Z.-L. Li, and J. Xia, "Generalized Split-Window Algorithm for Estimate of Land Surface Temperature from Chinese Geostationary FengYun Meteorological Satellite (FY-2C) Data," Sensors, vol. 8, pp. 933--951, 2008.

[15] C. Gao, B.-H. Tang, H. Wu, X. Jiang, and Z.-L. Li, "A generalized split-window algorithm for land surface temperature estimation from MSG-2/SEVIRI data," International Journal of Remote Sensing, vol. 34, pp. 4182-4199, 2013.

[16] G. M. Jiang and R. Liu, "Retrieval of sea and land surface temperature from SVISSR/FY-2C/D/E measurements," IEEE Transactions on Geoscience \& Remote Sensing, vol. 52, pp. 6132-6140, 2014.

[17] Z.-L. Li, B.-H. Tang, H. Wu, H. Ren, G. Yan, Z. Wan, et al., "Satellite-derived land surface temperature: Current status and perspectives," Remote Sensing of Environment, vol. 131, pp. 14-37, 2013.

[18] J. A. Sobrino, C. Coll, and V. Caselles, "Atmospheric correction for land surface temperature using NOAA-11 AVHRR channels 4 and 5," Remote Sensing of Environment, vol. 38, pp.19-34, 1991.

[19] F. Becker, and Z.-L Li, "Surface temperature and emissivity at various scales: Definition, measurement and related problems," Remote Sensing Reviews, vol. 12, pp. 225-253, 1995.

[20] C. François, and C. Ottlé, "Atmospheric corrections in the thermal infrared: global and water vapor dependent split-window algorithms-applications to ATSR and AVHRR data," IEEE Transactions on Geoscience and Remote Sensing, vol. 34, pp. 457-470, 1996.

[21] Z.-L. Li, H. Wu, N. Wang, S. Qiu, J. A. Sobrino, Z. Wan, et al., "Land surface emissivity retrieval from satellite data," International Journal of Remote Sensing, vol. 34, pp. 3084-3127, 2013.

[22] B.-H. Tang, K. Shao, Z.-L. Li, H. Wu, and R. Tang, "An improved NDVI-based threshold method for estimating land surface emissivity using MODIS satellite data," International Journal of Remote Sensing, vol. 36, pp. 4864-4878, 2015.

[23] X. Fan, B.-H. Tang, H. Wu, G. Yan, Z.-L. Li, G. Zhou, K. Shao, and Y. Bi, "Extension of the Generalized Split-Window Algorithm for Land Surface Temperature Retrieval to Atmospheres With Heavy Dust Aerosol Loading," IEEE Journal of Selected Topics in Applied Earth Observations and Remote Sensing, vol. 8, pp. 825-834, 2015.

[24] D. Mutiibwa, S. Strachan, and T. Albright, "Land Surface Temperature and Surface Air Temperature in Complex Terrain," IEEE Journal of Selected Topics in Applied Earth Observations and Remote Sensing, vol. 8, pp. 4762-4774, 2015. 
[25] P. J. Minnett, "A Numerical Study of the Effects of Anomalous North Atlantic Atmospheric Conditions on the Infrared Measurement of Sea Surface Temperature From Space," Journal of Geophysical Research Atmospheres, vol. 91, pp. 8509-8521, 1986.

[26] C. M. R. Platt and A. J. Prata, "Nocturnal effects in the retrieval of land surface temperatures from satellite measurements," Remote Sensing of Environment, vol. 45, pp. 127-136, 1993.

[27] J. P. Lagouarde, M. Irvine, and S. Dupont, "Atmospheric turbulence induced errors on measurements of surface temperature from space," Remote Sensing of Environment, vol. 168, pp. 40-53, 2015.

[28] A. Chedin, N. A. Scott, C. Wahiche, and P. Moulinier, "The Improved Initialization Inversion Method: A High Resolution Physical Method for Temperature Retrievals from Satellites of the TIROS-N Series," Journal of Applied Meteorology, vol. 24, pp. 128-143, 1985.

[29] W. L. Barnes, T. S. Pagano, and V. V. Salomonson, "Prelaunch characteristics of the Moderate Resolution Imaging Spectroradiometer (MODIS) on EOS-AM1," IEEE Transactions on Geoscience \& Remote Sensing, vol. 36, pp. 1088-1100, 1998.

[30] B.-H. Tang and J. Wang, "A Physics-Based Method to Retrieve Land Surface Temperature From MODIS Daytime Midinfrared Data." IEEE Transactions on Geoscience \& Remote Sensing, vol. 54, pp. 4672-4679, 2016.

[31] Z.-Q. Liu, Y.-P. Zhen, L.-I. Jing-Lin, J. Chen, and Z.-J. Yan, "Temperature inversion characteristics of low-air atmosphere of Urumqi City," Arid Land Geography, vol. 30, pp. 351-356, 2007. 